Travelling concepts: Performative movements in learning/playing

\author{
Barbara Simpson \\ Strathclyde Business School \\ University of Strathclyde \\ 199 Cathedral Street \\ Glasgow G4 OQU \\ UNITED KINGDOM \\ E: barbara.simpson@strath.ac.uk \\ Ph: +44 (0)1415536141 \\ Rory Tracey \\ Strathclyde Business School \\ University of Strathclyde \\ UNITED KINGDOM
}

and

Alia Weston

OCAD University

Toronto

CANADA

Management Learning

Accepted for publication

2 January 2018 


\section{Travelling concepts: Performative movements in learning/playing}

\section{Abstract}

This paper examines the generative interplay between learning and playing in managing and organizing by taking a performative approach that theorizes learning/playing as an assemblage in which playing and learning emerge as co-evolving processes in practice. Addressing the methodological challenges associated with this performative approach, the learning/playing assemblage is probed using travelling concepts, which attend to the dynamic movements rather than the stabilities of organizing, functioning as proposed by Vygotsky as both a research tool and an emergent result of research. This notion of 'travelling concepts' is developed empirically by engaging with Mead's 'sociality', which he defined as the simultaneous experience of being several things at once. Three interweaving strands of sociality - relational, spatial, and temporal - are elaborated in the context of travelling with and through four artisan food production sites, each of which sought to engage differently with the aesthetics and functionality of the food we consume.

\section{Keywords}

Travelling concepts, performativity, sociality, tool-and-result, artisanal food production 


\section{Introduction}

"When we are at work we ought to be at work. When we are at play we ought to be at play. There is no use trying to mix the two. The sole object ought to be to get the work done and to get paid for it. When the work is done, then the play can come, but not before" (Henry Ford quoted by West, 2014, p. 191).

For a long time this opinion, expressed here by one of the titans of industrialization, held sway in the organization and management literature. The very idea of play at work was dismissed as childish, time-wasting, inefficient, and altogether too frivolous for the serious business of work (Mainemelis \& Dionysiou, 2015; Sandelands, 2010). More recently, however, as management interests have shifted towards the problematics of learning and continuous change, researchers have had to innovate, both theoretically and methodologically, in order to gain better access to the inventive and creative dynamics of organizing. In this context, play has emerged as a legitimate area of inquiry in a variety of domains including organizational learning (Kolb \& Kolb, 2010), strategic innovation (Roos, Victor, \& Statler, 2004), leadership development (Kark, 2011), entrepreneurship (Hjorth, 2005), identity work (Ibarra \& Petriglieri, 2010), workplace fun (Bolton \& Houlihan, 2009) and humour (Warren, 2005a). Indeed the pervasiveness of play in contemporary organizational practice is well demonstrated by Latusek and Vlaar (2015), whose comparative studies in Poland, the Netherlands and the USA found playing was one of three persistent metaphors (the others being performing and fighting) that characterize how the work of managers is perceived. At the same time, play is increasingly valued in the practitioner domain, as exemplified by companies such as Google, 3M, LEGO and IDEO 
where play-time is explicitly figured in to working life (Mainemelis \& Ronson, 2006;

Thorsted, 2016).

This parallel development of scholarly and practitioner interest in play raises questions about research relevance that are particularly acute in the field of management learning (Sambrook \& Willmott, 2014). Specifically, what can be done to bridge the gap between theory and practice (Latusek \& Vlaar, 2015), and how might we collaborate to generate learning that has real impact? Much of the research to date has adopted a scientific, theoryprivileging mode of inquiry, where the primary concern has been to understand how play provides a context to support the accomplishment of specific ends (e.g. profit, productivity, new products, or developmental targets), and how the construct of play interacts with other related constructs such as creativity (Mainemelis \& Ronson, 2006). Arguably, however, it is this scientific approach that actually institutes the theory/practice gap in the first place, slicing and dicing the organizational field into discrete, dualistic categories that arrest the flow of practice in its tracks. By over-zealously reducing organizing to a by-the-book methodology, life is sucked out of practice and replaced with moribund constructs that are of little value to practitioners who are faced with immediate practical problems. Sandberg and Tsoukas (2011) suggested that if research is to be more practice-sensitive, there is a need for a practical rationality to complement conventional scientific rationality, one that invites new ways of theorizing and methodological approaches better equipped to engage with the ongoing, unfolding playfulness of practice.

In this paper, we respond to this invitation firstly by developing a performative understanding of playing that highlights the emergent dynamics of learning in organizational practice, and secondly by tackling the methodological challenge of researching such 
dynamics, introducing the notion of travelling concepts as a new class of empirical sensitization that attends to the movements rather than the stabilities of organizing. In pursuing these questions, we do not wish to take issue with the functional possibilities of play in organizational research, but we do suggest these approaches alone are not enough. There is much more to understand about the engaged responsivity of play than can be grasped by instrumental research that focuses solely on epistemic forms abstracted out of lived experience (Cunliffe, 2008; Ingold, 2011: Chapter 17; Shotter, 2016). As March (1979) argued, we need a playful 'technology of foolishness' to complement the serious 'technology of rationality' that currently dominates the organizational literature. Responding to this challenge, Thorsted (2016) advocated moving beyond the realism that underpins notions of play as a variable or a construct in theory, towards a processual ontology that recognizes the ongoing, relational continuity of human living wherein playing and learning are integral and co-emergent dynamics of organizing. Whilst this alternative ontology has attracted increasing attention from organizational theorists and philosophers (Helin, Hernes, Hjorth, \& Holt, 2014), critical questions remain about how to actually do empirical research that is informed by this perspective.

Our methodological argument borrows ideas about travelling concepts and mobilities from the social sciences. Urry (2007) argued for a 'mobility turn' that admits new mobile rules to guide sociological research, while Bal (2002) proposed travel as an animating principle that can bring concepts from a variety of different practices into mutual dynamic engagement. She argued that we need to set aside our fixation with the meanings of concepts in favour of understanding what it is that they do in practice. This performative orientation replaces the formalism of conventional methodology with something more akin to a traveller's 'rough guide' to the sites and sights encountered during an unfolding research journey. We take up 
these ideas firstly by framing the interplay between learning and playing - the learning/playing assemblage - as a performative move, which we then elaborate as a travelling concept by drawing on Vygotsky's (1978) 'tool-and-result' methodology and Mead's (1932) notion of 'sociality'. Our argument is illustrated using our own travellers' tales gathered as we journeyed through, and around, several small artisanal food producing businesses located in Scotland. The contributions that this paper makes are firstly a theorization of learning/playing as a performative assemblage, secondly the methodological development of sociality as a specific example of a travelling concept, and finally, the empirical elaboration of learning/playing in terms of three different expressions of sociality: relational sociality, spatial sociality, and temporal sociality.

\section{Learning/Playing and travelling concepts}

Play is already well-recognised across a number of different disciplines as an important aspect of understanding the social processes of learning. Broadly, the psychological literature views it as an activity that aids cognitive and emotional development; the educational literature emphasizes its importance as a key concept for learning, especially in early childhood; the sociological literature positions it as an activity in which engaged individuals imaginatively reconstruct the structures of society; and the anthropological literature views it as a process of cultural transformation (Statler, Roos, \& Victor, 2009). The common theme running through these various disciplinary perspectives is the link between play and the transformational processes of learning. As noted already, the organizational literature has engaged creatively with play in relation to a range of different learning problematics. This paper is similarly located at the intersection between play and learning, but the particular contribution we seek to make is in opening up the performative dimensions of these interweaving dynamics in the practice of organizing. 
The intricacy with which play is woven into the ordinary fabric of everyday living is suggested by the term Homo Ludens, coined by Huizinga (1955) to reflect the centrality of game-playing in the development of human culture. However, this seems to suggest 'games' and 'playing' are one and the same. Caillois (2001) contra-argued that games provide the context, structures, and rules that both facilitate and constrain the actions of playing. For instance, in the game of chess the board simulates a battlefield and each chess piece is coded with specific intrinsic properties that determine the moves it can make, thus defining the rules of play. Caillois associated this type of play with ludus, which is subordinate to, and disciplined by rules; by contrast paidia is dynamic, exuberant and spontaneous playing. In our view, ludus lends itself to a metaphysics of representation familiar to realist and constructionist researchers alike, which seeks to uncover and map the structures and rules of the game, whereas paidia is concerned with a performative metaphysics that attends to actions emerging in the experience of playing. Ludus and paidia offer complementary perspectives on play(ing), but here we have chosen to focus solely on the theoretical and methodological implications of paidia as it relates to learning in organizational practice. We argue that paidia provides access to playing as an ongoing process that travels and emerges with relationally responsive learning.

To theorise paidia we turn to sources that are explicitly performative in their underlying assumptions. We take inspiration from Lev Vygotsky (1978), particularly Holzman's (2009) close reading of his work. Vygotsky's interest in playing was originally stimulated by his observations of infants as they are learning to speak. He realized that in their babbling, babies are not only playing with words and language, but they are also progressively 
becoming selves as their new language worlds emerge. In effect, they are simultaneously playing-to-learn and learning-to-play. This learning/playing assemblage evokes an improvisational dynamic whereby beings are continuously transformed by becomings. In other words what is, provides a foundation for the creative improvisation of what is yet to be (Weick, 1998). As Holzman (2009) observed, in learning/playing we are actively performing who we are not and what we do not know as improvisational extensions of who we are now. Thus we understand learning/playing as a generative process that emerges at the interface between what is known and what is imagined as we performatively bring new worlds into being.

Paidia necessarily involves elements of fantasy and imagination developed improvisationally in relation to context-specific rules, which may themselves change as the imaginary situation develops (Vygotsky, 1978). Such fantasy-driven activity is perhaps most evident amongst pre-schoolers for whom the rules of play are not necessarily formulated in advance, but rather are invented as learning/playing proceeds and the imaginary situation evolves. Holzman (2009) argued though that as children progress through the school system and on into adulthood, they acquire working repertoires of routines that reduce their need to continue creating new performances of themselves. What started out as improvised performances become scripted, and we get stuck in performing certain roles that have proven to be effective, or at least adequate, in getting on with our daily living. To the extent that these learned skills enable us to act automatically, without thinking, imagination becomes superfluous, just as in a chess game where "overt rules clearly dominate over the imaginary situation of the contest among knights, queens, etc" (Holzman, 2009, p. 50). 
This is not to suggest, however, that paidia is the sole preserve of children and that all adults have necessarily lost this capacity for learning/playing. There are many forms of improvisational performance in music, theatre, and sport, where players across the developmental spectrum from childhood to adulthood very productively engage each other in creative practice. Equally, the learning/playing assemblage is abundantly evident in organizational contexts, where learning arises out of the generative complex of playful actions taken by people as they endeavour to coordinate their efforts. Summarising our argument so far then, we propose a dynamic theorization of learning/playing in which playing and learning are co-evolving processes that invoke improvisational performance, generative experimentation, and creative inquiry.

\section{The methodological challenge}

Accessing this learning/playing assemblage in organizational research, however, raises some difficult methodological challenges. Studying paidia obliges us as researchers to set aside our sophisticated definitions, frameworks and theories in order to connect with a more child-like approach to learning in the playfulness of the moment. As Shotter (2006) explained, we need to liberate ourselves from 'aboutness-thinking', which considers processes as 'over there' outside ourselves, and get immersed in 'withness-thinking', which seeks to engage with relationally responsive improvisations as they happen (see also Cunliffe, 2008). Holzman argued that developing a methodological sensitivity to this performance dynamic requires us to transcend the conventions of "tool for result methodology" (2009, p. 9), which makes a dualistic separation between the tools we use to assess and measure situations and the results that these tools produce. Following Vygotsky, she contrasted this dualistic approach with a "tool-and-result methodology" where both 
tool and result are continuously co-produced in the flow of research practice. As Vygotsky (1978, p. 65) observed:

"The search for method becomes one of the most important problems of the entire enterprise of understanding the uniquely human forms of psychological activity. In this case, the method is simultaneously prerequisite and product, the tool and the result of the study."

A similar methodological argument has been advanced by Barad (2003), who focussed on "the apparatus" as both definitional of method and also constituted by method. For her, apparatuses:

"are not inscription devices, scientific instruments set in place before the action happens, or machines that mediate the dialectic of resistance and accommodation. They are neither neural probes of the natural world nor structures that deterministically impose some particular outcome ... [they] are not mere static arrangements in the world, but rather apparatuses are dynamic (re)configurings of the world, specific agential practices/intraactions/performances through which specific exclusionary boundaries are enacted" (Barad, 2003, p. 816, italics in original).

Both Barad and Holzman, in their efforts to go beyond conventional methodological thinking, have pursued an alternative research philosophy that challenges the roots of paradigmatic thinking and urges us to reconsider our approaches to researching the performativity of our own and others' ongoing practice. Building on their ideas, our goal here is to propose a tool-and-result apparatus that enables empirical engagement with the performative dynamics of the learning/playing assemblage in the practice of organizing. 
How then can we research a world that is always already on the move (Urry, 2007), and how might we "enter into a relationship with living forms ... making ourselves open to their movements" (Shotter, 2000, p. 233)? We propose 'travelling concepts' as a way of sensitizing the researcher's empirical gaze to the movements of learning/playing s/he encounters and responds to in the living practice of organizing. In this, we are building on the sociological notion of theory as a "sensitizing concept" (Blumer, 1954, p. 7) or "sensitizing device" (Giddens, 1989, p. 294). Whereas the physical sciences are generally described in terms of what Blumer called "definitive concepts" $(1954$, p. 7), which provide precise prescriptions of what the researcher is to look for, the social sciences invite a more interpretive form of engagement in which concepts serve as suggestions that sensitize researchers to the relevant features of their inquiries. With travelling concepts, we seek to go beyond mere sensitization to the features of context, focussing more specifically on the movements and flows that emerge in the dynamics of learning/playing. Travelling concepts permit multi-directional engagement in empirical experience, recognising that research methods form part of the landscape being traversed (Law \& Urry, 2004). They offer ways of engaging with the movements through which "life takes shape and gains expression in shared experiences, everyday routines, fleeting encounters, embodied movements, precognitive triggers, practical skills, affective intensities, enduring urges, unexceptional interactions and sensuous dispositions" (Lorimer, 2005, p. 84). Bal (2002) presented travelling concepts as less concerned with univocal meanings and more with the performative work that they do as they travel. That is, they are the tools-and-results of inquiry. It is their very elasticity and chameleon-like capacity for change that makes them useful as travellers' aids and a worthy addition to a 'rough guide' to the sites visited and sights seen on the research journey. 
At the centre of our understanding of learning/playing is the elastic and changeful concept of continuously performing-becoming selves as described by Vygotsky. Whilst his work was primarily directed towards early childhood development, it resonates with the thinking of George Herbert Mead, who also placed learning at the heart of social becoming (Valsiner \& van der Veer, 2000). Whereas conventional wisdom would posit selves as products of the mind, Mead (1934) argued the opposite, that consciousness arises out of the actions of selves that are always already constituted in the everyday performative toing-and-froing of conversation. Selves are, therefore, necessarily social rather than individual phenomena, which act as tools-and-results in ongoing processes of engagement and inquiry. It is precisely because selves are already socially constituted that we are able to engage playfully in responsive dialogue, imagining the attitudes of others, seeing situations as others might, and having experiences 'as if' we are who we are not. We have found Mead's notion of "sociality", which he defined as "the capacity of being several things at once" (1932, p. 75), to be particularly useful as a means of opening up learning/playing to reveal its tool-andresult underpinnings. In Mead's view, for any event to qualify as 'social' it must exist simultaneously in two different referential frames (see also Joas, 1997). It is sociality that allows us to be relationally responsive as we enter into, and move within the worlds of others, so it is the movements of sociality that guide us as researchers as we seek to capture the unfolding dynamics of learning/playing. We now proceed to present some empirical illustrations in which our researchers' gaze has been sensitized to movements of sociality encountered on our research travels. 


\section{Modes of travel}

Addressing the methodological questions raised by this approach to learning/playing cannot be simply a matter of defining specific tools or methods, as our apparatuses must comply with our underlying assumptions about performativity and practice. Travelling concepts aim to engage with a world already on the move (Urry, 2007), so their implementation requires a shift away from a methodology that brings practices to a standstill, and towards an alternative that moves alongside and amongst these evolving concepts. In Vygotsky's articulation of tool-and-result methodology we find a starting point that shares common ground with more recent inquiries into the co-production of research and practice (Barad, 2003; Law \& Urry, 2004). A central concern for these writers has been to attend not only to what methods produce, but also to how they act. The unconventional demands implied by this approach lead us to inquire into the learning/playing socialities of our research participants, which we access using a research design that combines conversational narratives (Czarniawska, 1998; Riessman, 2008) and visual inquiry (Bell \& Davison, 2013; Harper, 2002; Warren, 2005b). Our reasoning for adopting this particular design is firstly, through the use of narratives, we are seeking to engage with similar processes of understanding to those used by our research participants as they organize and come to terms with their own experiences (Boje, 1991; Czarniawska, 1998; Tsoukas \& Hatch, 2001). Narratives can function as tool-and-result inquiries, acting as both the outcome of research and the means through which these outcomes are realized. This quality emphasises how narratives "create the very events they reflect upon" (Denzin, 2000, p. xii), linking decisive moments, recurrent themes, and connections within practice (Bruner, 1986). By sharing and questioning these narratives in the research process, our own understandings as well as those of the participants were further developed and refined. 
Secondly, we used visual inquiry to help access the less obvious, repetitive or habitual aspects of organisational practice, which often pass unnoticed or unspoken. Within the everyday minutiae of organizational life lie opportunities for creative and playful engagement, which we were eager to explore. Of particular relevance to our research design were the ways in which visual images could be used performatively to stimulate participants' imaginations and memories (Bramming, Hansen, Bojesen, \& Olesen, 2012; Steyaert, Marti, \& Michels, 2012) rather than merely as representations of their experiences. Accordingly, we do not reproduce any of these images here because what they represent is less relevant than the narrative conversation that they stimulated. Our ambition was to use photographic images gathered by our participants to challenge them to look again at their everyday experience, while at the same time allowing us to enter more deeply into their dialogical worlds. Participant-generated photographic images acted as interventions into our narrative conversations, generating a richer quality of dialogical engagement as participants negotiated their own learning/playing activities.

\section{Sites of travel}

Our empirical sites are located within the artisan food sector. Food has already sparked interesting debates in the organizational literature (Pina e Cunha, Cabral-Cardoso, \& Clegg, 2008 ) including topics such as the emergence of new gastronomic practices (Gomez \& Bouty, 2011) and the function of creativity in situated learning (Stierand, 2015). Food also has an inherent sociality that people engage with together on a daily basis. This sociality is exemplified in a multitude of ways from the storying of food to the processes of buying and eating food in places like food markets. 
The empirical material presented here has been extracted from a larger study of creative practice. It relates to four specific sites where we acquired narratives and images over a three-month period. Ethical approval for this study was granted by the University of Strathclyde Ethics Committee, participants were fully informed, in writing, about the nature of the study and their role in it, and they had the opportunity to ask questions before giving their signed consent to take part. They were invited into narrative conversations that took place at a variety of on- and off-site locations, were loosely structured, focused on key events, products and participants' stories, and guided primarily by what the participants themselves considered important. Our aim was to provide a platform for them to present both their own stories and the playful, creative activities that made those stories possible. We then asked participants to take photos over the next 4-6 weeks of their everyday creative and playful engagements at work. These photographs were used in a second narrative conversation to both stimulate participants' imaginations, and also to allow us to become more open to their stories. Our assumption was that neither the narratives nor the photographs actually reproduced reality, but rather they acted as tools-and-results in "normative, intervening research that touches, manipulates, impacts and experiments with the field" (Bramming et al., 2012, p. 58). The narrative data was subsequently interrogated by following the breaks and connections in participants' descriptions of events, then organizing these into episodes of sociality.

Our first research site featured Alan and Sarah ${ }^{1}$, a pair of entrepreneurs who had both left full time employment to pursue their dream of a mobile coffee outlet, which took the form

\footnotetext{
${ }^{1}$ Participants' names have been anonymized
} 
of two Volkswagen camper vans retrofitted with espresso machines. The colourful vans were a regular feature at local farmers' markets, but our research was primarily conducted at a side-project which saw Alan and Sarah installing coffee machines within a community space used for up-cycling old furniture. Our second site belonged to Janu, who specialized in Bombay style street food. Also operating at a local farmers' market, Janu hosted pop up food events, taking over cafés and spaces to produce themed nights based on her Bombay style dishes. Central to Janu's project was the aim of remaining true (and introducing British palates) to what she considered authentic Bombay cuisine, inspired both by her childhood experiences of street vendors and her family's cooking.

At our third site, David specialized in the production of unusual condiments. We were intrigued both by David's array of different chutneys, jams and preserves, and the accompanying back story for each one. A recent university graduate keen to avoid the monotony of office work, David's time was split between market stalls, a production space to achieve the appropriate scale, and a tester kitchen in his flat for trying out new ideas. Staunchly opposed to what he saw as unnecessary conformism within the condiment market, David was passionate about high quality products and the provenance of his ingredients. The fourth and final site involved Penny and Alice working from a small production kitchen to produce artisan chocolates and caramels. The centrepiece of the kitchen was a large marble slab, upon which chocolate could be tempered and shaped. Surrounding the slab were trays for the finished product to cool, and an array of botanicals that were added to the chocolate during processing. Throughout the week the kitchen was used for making products, but on weekends it was opened to the public, allowing Penny and Alice to sell their wares. 


\section{Sights of travel}

In this section, we explore learning/playing as experienced in our travels with the participants at our various research sites. Our aim was to understand how these food producers engage learning/playing in the everyday development of their businesses. We used Mead's sociality as a specific travelling concept to sensitize ourselves to the movements that arose in the conversational narratives when our participants were "being several things at once" $(1932$, p. 75). As we immersed ourselves in the activities of our artisanal food producers, we came to realise three different aspects of sociality were in play: 'relational sociality' relates to experiencing 'as if' being simultaneously both selves and others; 'spatial sociality' is concerned with experiencing 'as if' being simultaneously in one place and another; and 'temporal sociality' refers to experiencing 'as if' being simultaneously both before and after. The teasing out of sociality into three different aspects shows how this travelling concept may be transformed as it progressively performs the becomings of emergent beings. Our presentation of the sights seen on our research journeys is structured using these three empirical aspects. We hasten to add though, that they should not be treated as discrete and separate dynamics; rather they are continuously interweaving in the learning/playing assemblage. We separate them here purely as a heuristic device.

\section{Relational sociality}

Our starting point is to consider those relational dynamics of learning/playing that draw the researchers' gaze towards the simultaneity of selves and others in social interaction, and the ways in which differences between relational frames generate new realizations. Here we are looking for evidence of learning/playing arising out of situations where selves engage 
imaginatively with what other selves may be experiencing. In this section we explore how this takes place through intense conversations, the intersecting of diverse experiences, and shared humour.

For instance, chocolatiers Penny and Alice, formed ideas through intense conversations, which they referred to as 'storming':

Alice: Our ideas often don't form in a one-er like; "I'm going to have an idea!" ... We go storming!...basically that means we walk somewhere, so it could be the orchard or it could just be my house or something, but we storm, we walk and talk the whole way, and usually have excellent ideas.

Penny: I think it took about a year of talking about things... seeing [the business] just as a dream rather than a goal. And it happened really, really slowly and we kind of accidently fell into it becoming a real life tangible thing, rather than just something we were just messing around with, doing for fun on the side.

Their 'storming' conversations allow them to play with, and learn from, each other's experiences, inviting each of them to extend who they are at present by opening up to new possibilities 'as if' being the other. Their relational experiences are a form of improvisation (Weick, 1998) that takes place in the context of learning/playing, where they perform what is not yet manifest, trying it out 'as if' it already exists.

Alice and Penny draw upon varied and eclectic interests that inspire their chocolatiering. Each brings different experiences to their work together, one having previously worked in film production and the other in perfume-making. Storming allows them to creatively explore their intersecting experiences. In doing so, they find new stimuli to their creative work together, which offers opportunities for collaborative development: 
Penny: You know we want to make our own essential oils, that would be great and just a couple of drops can make one really magic chocolate. I think people want to own this; they want to taste this and own it and we live to make this world. And I just have to make chocolate, I have to process something Alice: I think that links to films ... that's what films do, you make a world and you are immersed in it when you watch the film, and we want to make those same feelings as we get when we watch films

Through this experience, they bring a strong sensory and emotional quality to their chocolatiering, which in turn is infused into their fantastical and unexpected chocolate creations, and is ultimately transmitted to customers who consume the chocolate. Mead (1934) referred to this experience of sociality as taking the role or the attitude of the other, or as standing in the shoes of the other. This creates an intense 'withness' of relationally responsive conversation (Shotter, 2006), providing Alice and Penny with a vehicle for improvisation, learning/playing with new performances of themselves, indulging their fantasies, and developing their becoming business.

Relational sociality can also be seen in the ways humour is used to move beyond a literal interpretation of reality to allow for an imaginative re-presentation of affairs. Alan and Sarah told how they engage in exactly this sort of activity when imagining their complementary, but often hilariously incongruent roles within the business:

Sarah: In my head, what our set-up is basically he's the mad coffee professor running around in circles and making stuff; and I'm like following around behind, fixing it and organizing it! [both laugh] That's basically how it is. 
Alan: Sometimes we balance each other out and at some stages encourage crazy ideas, whoever it might have come from

Here humour is used to signal ambiguous or unexpected shifts in the conversational flow that enable new ideas to be surfaced and explored. Just as for Alice and Penny's aesthetic sensibilities, there is a strong feelings component to humour. Vygotsky (1978) showed how humour helps players to venture beyond the cognitive rules and structures of their games (ludus) into new and imaginative ways of becoming through learning/playing. Humour generates learning/playing by highlighting the ambiguities brought forward by sociality.

Relational sociality, the ability to switch roles, to see situations through different lenses, to create different relational dynamics, and to go beyond what is given directly to experience is thus crucial to understanding the learning/playing of our artisanal food producers.

\section{Spatial sociality}

The notion of sociality also incorporates spatial difference and the imaginative potential of being 'as if' in more than one space at a time. Spatial sociality is reflected in our food producers' attempts to engage with meaningful spaces by either imagining beyond unconducive places or deliberately exploiting the opportunities offered by different spaces and diverse social situations.

For our participants, learning/playing often involved a choice to move outside the conventional spaces and places of paid work. When discussing the circumstances that led to their artisanal businesses, they were clear that newfound opportunities for creative learning/playing emerged through spatial sociality as a necessary response to the restrictions of their previous work places. Although they recognized the potential risks associated with working outside the regular parameters of secure work, they were also able 
to imagine engaging in new spaces that offered the freedom to experiment and be creative.

For instance, Janu and Alan both spoke about how they changed jobs from spaces that were not conducive to creativity, to new, more playful spaces that they constructed for themselves:

Janu: You couldn't be creative. So if I had an idea of how to do something, it was always bogged down with policies, procedures, rules, 'this is the only way you can do it, you can't do it any other way, because it's never been done before and we don't want to do it that way', you know, so it wasn't really my choice ... I found it boring ... because it's so micro-managed, so what you say really doesn't count, you're just there to do a specific job, if you're not there someone else will do it, so really it's not a space to be creative.

Similarly Alan articulated a new sense of space as he made the choice to leave his former employment:

Alan: I was just desperately unhappy. I was tired of working 7 days a week and not going anywhere with it, spending my weeks doing damage control and my weekends running markets so for me it was either create something new or go home ... So, I just thought this is not for me anymore, I don't want to live my life earning a half decent income and being miserable ... so in August, I just packed my stuff.

It is important to be able to create a meaningful space, a heterotopia (Hjorth, 2005), that is conducive to improvisational play. As Janu and Alan have indicated, spatial sociality means moving out of unconducive spaces and into spaces that foster creativity. During our conversations, their demeanour changed when they spoke of these different spaces. We 
could sense Janu's demoralization in her previous job, but her tone became more excited when she talked through pictures of Bombay street food, and her experience of setting up her business. We could similarly pick up on Alan's frustration about the lack of creativity in his previous job, but he lightened up considerably when he spoke about working full-time on his retrofitted coffee camper vans.

For others, spatial sociality is associated with finding space to be generative by alternating between different types of working spaces. Penny and Alice told how they use their kitchen space for production, but use a quite different space for generating new ideas:

Penny: [ideas] don't really happen in the kitchen, when you're standing there with all the ingredients in front of you it's like "I could do a new thing!" but I've forgotten all the ideas I've ever had in my whole entire life and now I need to go for a walk, talk about it ...

Alice: the kitchen - it's about production. It's a beautiful place to be but it's about making something we've already decided, when I'm there I don't want new ideas, I'm figuring out the process, how best to make stuff and things like that whereas ideas like the flavours and things like that, yeah they do need to be separate, and I suppose that is what we're doing, were taking ourselves away from computers, kitchens, not eating any chocolate ...

For Alice and Penny then, the space of production is necessarily very different from the space of idea generation. Bouty and Gomez (2015) similarly showed that access to a variety of different types of working space was important to Michelin starred chefs. Spatial sociality allowed them to move with ease and agility between different spaces that offered innovative possibilities in their kitchens. 
Equally, fleeting social situations may afford valuable opportunities to develop spatial sociality. David talked about gaining inspiration from experiencing different environments and people which trigger learning/playing experiences for him:

David: if I'm in a supermarket I'll see new products, if I'm in a farm shop... you've just got all this external medium, that makes you think in different ways, rather than just staring at a blank wall, or a computer screen!

David's engagement with different spaces is similar to Penny and Alice's storming, but whereas they went to the same beautiful space, David sought out many varied spaces. David's description illustrates the importance of performatively engaging with diverse social spaces that enable creative reconfiguration. By moving beyond a literal interpretation of things as always present, David finds the freedom to play with the resources offered by different settings, making new improvisational connections, and bringing new ideas to light.

These examples show that our food producers used spatial sociality to explore different ways of relating to their working spaces. Sometimes spaces were not conducive to creativity, so learning/playing involved the sociality of imagining 'as if' they moved to a new space where creativity could occur. In this way, their attempts to engage with a meaningful space enabled them to reconfigure the way they work through learning/playing. At other times, spatial sociality involved generating new performances by occupying different spaces for different purposes. These movements offer the freedom to re-imagine learning/playing using different social spaces as imaginative resources.

\section{Temporal sociality}

Whilst the re-imagining of relationships and spaces may lead to creative outcomes, the dynamic unfolding of learning/playing demands that we also explore the processes of 
temporal emergence (Garud, Simpson, Langley, \& Tsoukas, 2015). Analysing accounts of how the food producers created new things, it became apparent that their outputs were often the result of a performative moment in which pasts and futures entered simultaneously into their experience, allowing them to move beyond literal understandings in order to play with existing resources and create something new (Simpson, Buchan, \& Sillince, 2017). We found that temporal sociality was expressed at our research sites through the confluence of ideas, retrofitting of technology, and engagement with memories.

A moment involving the confluence of ideas occurred in the development of David's growing range of artisanal condiments. As a talking point David proudly revealed the label of his newest unusual marmalade and explained how the new flavour had come about:

David: It actually started with a meeting with a consultant ... he said you need to have more specific ranges. I already had the one whisky jelly ... okay maybe one more would do, what kind of marmalade could I do? And I think I was listening to Leonard Cohen at the time, and 'Suzanne' came on, and I just thought there we go, it's tea and oranges, there's the answer to my question. And it was as simple as that really. Leonard was singing away and I thought there we go, "all the way from China"

Here we see David idling, apparently aimlessly listening to music, while a new product slowly takes shape in his imagination. In this moment, we observe the coming together of past experiences and future imaginings; Leonard Cohen, the consultant's advice, the orientation to the problem at hand, the music being played, all coming together in a playful reinterpretation of 'Suzanne' as a recipe for a new 'tea and oranges' marmalade. 
Another example of temporal sociality was provided by Alan as he talked about his passion for converting old camper vans into a very contemporary coffee experience. Our conversation took place at their workshop amidst the workings of the retrofitted machinery. As we spoke, Alan and Sarah illustrated their narrative with pictures they had taken of their Volkswagen camper van and a coffee machine:

Alan: I loved building these vans, it was great fun. And I think for us with the vans and the roasters and the espresso machines it's all old school technology that we just update and rejuvenate and recreate and reinvent in many ways. I think reinvention, alongside improvisation is our core business ... it's the whole ethos around it, let's take the old, bring it up to date and let's showcase it ...

Their business concept then, sits within the interplay between past technologies and ongoing development into the future. This temporal sociality provides continuity to the plans that Alan and Sarah were making for their business, evoking the improvisational dynamic of learning/playing in which being is transformed by (re)imagined futures (Vygotsky, 1978).

Finally, temporal sociality draws on memories as a stimulus for future actions. Temporal sociality as re-enacted memory is exemplified in Alice's description of the development of a new type of chocolate:

Alice: one of my favourite chocolates we made at Christmas ... that came about because we were walking somewhere or sitting outside and talking about Christmas when we were kids, and the kind of things that we ate then and our favourite one ... was kind of based on those pfeffernusse cakes... they were something that my dad used to buy every single Christmas, I remember how 
excited I used to get when it was time to eat those cakes, [and] you get the memory when you taste it.

We see Alice contemplating her childhood memories, using these in the creative development of new ideas that will enhance the future of their chocolatiering business. Here learning/playing manifests through the temporal engagement with childhood memories that enable past and future actions to playfully interact. This reflects the temporalities that play out, for instance, in family businesses that continue to trade across generations, drawing family history and stories forward into new becomings (e.g. Dodd, Anderson, \& Jack, 2013).

Temporal sociality attends to being simultaneously both before and after, in memory and in anticipation. As highlighted, this ability was expressed by our food producers through the confluence of past and present ideas, the retrofitting of technology by bringing the old upto-date, and the playful transformation of past memories into future opportunities. For all of our food producers, these dynamics involved a performative moment in which pasts and futures came together and enabled them to move beyond literal understandings, creating something new by engaging temporal sociality in their learning/playing.

In summary, our analysis illustrates how the concept of sociality travels as three distinct, but interwoven aspects: 'relational sociality' relates to being 'as if' simultaneously both selves and others; 'spatial sociality' is concerned with being 'as if' simultaneously in one place and another; and 'temporal sociality' attends to being 'as if' simultaneously both before and after. Although presented here as separate dynamics, they continuously interweave in everyday practice as co-evolving processes that evoke improvisation, imagination and creativity. 


\section{Souvenirs of our travelling}

The journey described in this paper is an exploration of the notion of 'travelling concepts', particularly in relation to the performativity of the learning/playing assemblage. Our inquiry is motivated by frequent critiques of the organization studies and management learning literatures that something is missing, something is obstructing our scholarly engagement with the dynamics of living practice, and this obstruction is standing in the way of doing research that is relevant to, and has impact in the world of practice (Latusek \& Vlaar, 2015; March, 1979; Sandberg \& Tsoukas, 2011). We are by no means the first to respond to this critique by proposing a departure from the representationalist conventions that dominate organizational research (e.g. Helin et al., 2014; Shotter, 2006), but we have endeavoured to take a further tentative step towards understanding how performative and processual theories may actually be operationalized in empirical research. Borrowing from adjacent social science disciplines, we suggest 'travelling concepts' as a general class of methodological apparatus, which function as tools-and-results in performative research. We then elaborate this general classification using Mead's notion of 'sociality' as a specific example of learning/playing. Our empirical illustrations deepen this understanding by demonstrating three different ways of "being several things at once" (Mead, 1932, p. 75), namely relational sociality, spatial sociality, and temporal sociality.

Developing this argument has necessarily involved a rethinking of both theoretical and methodological assumptions, which are intricately intertwined in any research endeavour. We therefore claim inter-related contributions to theory and methodology. Firstly, we articulate a performative theory of what we have called the learning/playing assemblage, or paidia, which stands in contrast to the many representational theories of play and games 
(ludus) that currently dominate related literatures across multiple disciplines. These representational theories are generally oriented towards defining causal relationships between, or explanatory mechanisms involving clearly differentiated theoretical constructs; but arguably these constructs are themselves the obstacles to more relevant and impactful research as they are abstracted out of living experience, thereby losing any sense of mobility, or indeed life (Barad, 2003; Shotter, 2016). The performative alternative that we propose is intended to engage directly with the emergent experience of actions as they arise in the natural flow of practice, but this requires a very different type of theorization. To this end, we draw on the explicitly performative theorizations of Vygotsky (1978) and (Mead, 1932), as well as others who have sought to work in performative ways (e.g. Bal, 2002; Ingold, 2011; Shotter, 2006; Thorsted, 2016; Urry, 2007), to open up a more dynamic understanding of learning/playing as an ongoing social process of becoming. In particular, we argue that it is in the improvisational performance of learning/playing that what is, can be transformed into what is yet to be.

Secondly, we propose a methodological approach that complements this performative theorization of learning/playing. In this, we recognize that methodology is more than just a collection of research methods; indeed methods are generally understood simply as tools for research, whereas it is methodology that provides justification for the tools selected, as well as guidance in how these tools may be applied within a given philosophical context. In other words, methodology is a philosophical term whereas methods are technical and instrumental. Following Vygotsky (1978), Holzman (2009) and Barad (2003), we seek a methodology in which the tools used to access insight are, at the same time, the results of inquiry. Our choice to use narrative conversations enhanced by participant-generated photographs provides a way for us to enter into the flow of our participants' experiences 
and to develop sociality with them. These same methods might equally be employed in a representational study; the difference is in how the underlying metaphysical assumptions shape the ways results are used and the types of insights generated. The specific 'travelling concept' that we use in interpreting the results of our inquiry is 'sociality', which is an inherently processual phenomenon that produces insight into the dynamic unfolding of participants' experiences. Thus we bring our theory and methodology together as a coherent, tools-and-results, performative and processual research practice.

Our study also offers a third contribution, to the empirical domain of learning/playing in the creative practice of artisan food producers. Quite contrary to the epigraph with which we opened this paper, the three different aspects of sociality that we tease out suggest ways in which our participants invoked imagination and fantasy in their everyday work. Specifically, relational sociality refers to the experience of being simultaneously self and other 'as if' standing in the other's shoes; spatial sociality emerges from the experience of being simultaneously in more than one place 'as if' standing with a foot in each location; and temporal sociality arises in the experience of being simultaneously in several distinct time frames 'as if' travelling on more than one journey at a time. These three strands of sociality allow us to elaborate the subtle dynamics that creatively constitute learning/playing as they swirl together in the continuity of emergent practice. Each aspect of sociality plays across boundaries between people, spaces, and temporalities, not so much as a bridging or integrating mechanism, but rather as a generative dance (Cook \& Brown, 1999) that engages imagination in the continuity of action. This insight reminds us that creative practice can be resourced by people, spaces and/or temporalities, all of which offer imaginative possibilities for emerging sociality. 
In writing this paper we have adopted a novel structure and an unusual use of language because we suggest that performative research requires not only new theory and new methodology, but also new ways of communicating its insights. We have aimed to keep the journeying metaphor alive in order to produce travellers' tales that record some of the sights we have seen at the various sites we have travelled through. We hope that our attempts to produce a 'rough guide' that is more-than-representational (Lorimer, 2005) will encourage our readers to embark on their own travels, aided by travelling concepts that attend to the movements, rather than the structures, of learning/playing. We suggest that this type of approach is particularly relevant in the many 'as-practice' threads of inquiry in the contemporary literature on organizing (e.g. Chia \& MacKay, 2007; Nicolini, Gherardi, \& Yanow, 2003; Raelin, 2016). 


\section{References}

Bal, M. (2002). Travelling concepts in the humanities: A rough guide. Toronto: University of Toronto Press.

Barad, K. (2003). Posthumanist performativity: Toward an understanding of how matter comes to matter. Signs, 28(3), 801-831.

Bell, E., \& Davison, J. (2013). Visual Management Studies: Empirical and Theoretical Approaches*. International Journal of Management Reviews, 15(2), 167-184.

Blumer, H. (1954). What is wrong with social theory? American Sociological Review, 19(1), 3-10.

Boje, D. M. (1991). The Storytelling Organization: A Study of Story Performance in an Office- Supply Firm. Administrative Science Quarterly, 36(1), 106-126.

Bolton, S., \& Houlihan, M. (2009). Are we having fun yet? A consideration of workplace fun and engagement. Employee Relations, 31(6), 556-568.

Bouty, I., \& Gomez, M.-L. (2015). Creativity at work: Generating useful novelty in Haute Cuisine restaurants. In R. Garud, B. Simpson, A. Langley, \& H. Tsoukas (Eds.), The emergence of novelty in organizations (pp. 216-241). Oxford: Oxford University Press.

Bramming, P., Hansen, B. G., Bojesen, A., \& Olesen, K. G. (2012). (Im)perfect pictures: Snaplogs in performativity research. Qualitative Research in Organizations and Management, 7(1), 5471.

Bruner, J. S. (1986). Actual minds, possible worlds. Cambridge, MA: Harvard University Press.

Caillois, R. (2001). Man, play and games (M. Barash, Trans.). Urbana and Chicago: University of Illinois Press.

Chia, R., \& MacKay, B. (2007). Post-processual challenges for the emerging strategy-as-practice perspective: Discovering strategy in the logic of practice. Human Relations, 60(1), 217-242.

Cook, S. D., \& Brown, J. S. (1999). Bridging epistemologies: The generative dance between organizational knowledge and organizational knowing. Organization Science, 10(4), 381-400. 
Cunliffe, A. (2008). Orientations to social constructionism: Relationally responsive social constructionism and its implications for knowledge and learning. Management Learning, 39(2), 123-139.

Czarniawska, B. (1998). A narrative approach to organization studies (Vol. 43). Thousand Oaks, CA: Sage.

Denzin, N. K. (2000). Foreword. In A. Treacher, C. Squire, M. Andrews, \& S. Sclater (Eds.), Lines of Narrative. London: Routledge.

Dodd, S. D., Anderson, A., \& Jack, S. (2013). Being in time and the family owned firm. Scandinavian Journal of Management, 29(1), 35-47.

Garud, R., Simpson, B., Langley, A., \& Tsoukas, H. (2015). How does novelty emerge? In R. Garud, B. Simpson, A. Langley, \& H. Tsoukas (Eds.), The Emergence of Novelty in Organizations (pp. 124). Oxford: Oxford University Press.

Giddens, A. (1989). A reply to my critics. In D. Held \& J. B. Thompson (Eds.), Social theory of modern societies: Anthony Giddens and his critics (pp. 249-301). Cambridge: Cambridge University Press.

Gomez, M.-L., \& Bouty, I. ( 2011). The Emergence of an Influential Practice: Food for Thought. Organization Studies, 32(7), 921-940.

Harper, D. (2002). Talking about pictures: A case for photo elicitation. Visual Studies, 17(1), 13-26.

Helin, J., Hernes, T., Hjorth, D., \& Holt, R. (Eds.). (2014). The Oxford Handbook of Process Philosophy and Organization Studies. Oxford: Oxford University Press.

Hjorth, D. (2005). Organizational entrepreneurship with de Certeau on creating heterotopias (or spaces for play). Journal of Management Inquiry, 14(4), 386-398.

Holzman, L. (2009). Vygotsky at work and play. London and New York: Routledge.

Huizinga, J. (1955). Homo ludens: a study of the play-element in culture: Beacon Press.

Ibarra, H., \& Petriglieri, J. L. (2010). Identity work and play. Journal of Organizational Change Management, 23(1), 10-25. 
Ingold, T. (2011). Being alive. Oxford and New York: Routledge.

Joas, H. (1997). G.H.Mead - A contemporary re-examination of his thought. Cambridge, MA: MIT Press.

Kark, R. (2011). Games managers play: Play as a form of leadership development. Acdemy of Management Learning \& Education, 10(3), 507-527.

Kolb, A., \& Kolb, D. (2010). Learning to play, playing to learn: A case study of a ludic learning space. Journal of Organizational Change Management, 23(1), 26-50.

Latusek, D., \& Vlaar, P. W. (2015). Exploring managerial talk through metaphor: An opportunity to bridge rigour and relevance? Management Learning, 46(2), 211-232.

Law, J., \& Urry, J. (2004). Enacting the social. Economy and society, 33(3), 390-410.

Lorimer, H. (2005). Cultural geography: the busyness of being 'more-than-representational'. Progress in human geography, 29(1), 83-94.

Mainemelis, C., \& Dionysiou, D. (2015). Play, flow, and timelessness. In C. Shalley, M. Hitt, \& J. Zhou (Eds.), Oxford Handbook of creativity, Innovation, and Entrepreneurship: Multilevel linkages (pp. 121-140). New York: Oxford University Press.

Mainemelis, C., \& Ronson, S. (2006). Ideas are born in fields of play: Towards a theory of play and creativity in organizational settings. Research in Organizational Behavior, 27, 81-131.

March, J. (1979). The technology of foolishness. In J. March \& J. Olsen (Eds.), Ambiguity and choice in organizations. Oslo: Universitetforlaget.

Mead, G. H. (1932). The philosophy of the present. Illinois: La Salle.

Mead, G. H. (1934). Mind, self and society Chicago: University of Chicago Press.

Nicolini, D., Gherardi, S., \& Yanow, D. (Eds.). (2003). Knowing in organizations: A practice-based approach. London and Armonk, NY: M.E. Sharpe.

Pina e Cunha, M., Cabral-Cardoso, C., \& Clegg, S. (2008). Manna from heaven: The exuberance of food as a topic for research in management and organization. Human Relations, 61(7), 935963. 
Raelin, J. A. (Ed.). (2016). Leadership-as-Practice: Theory and application: Routledge.

Riessman, C. K. (2008). Narrative methods for the human sciences: Sage.

Roos, J., Victor, B., \& Statler, M. (2004). Playing seriously with strategy. Long Range Planning, 37(6), 549-568.

Sambrook, S., \& Willmott, H. (2014). The rigor of management education and the relevance of human resource development: Natural partners or uneasy bedfellows in management practice? Management Learning, 45(1), 39-56.

Sandberg, J., \& Tsoukas, H. (2011). Grasping the logic of practice: Theorizing through practical rationality. Academy of Management Review, 36(2), 338-360.

Sandelands, L. (2010). The play of change. Journal of Organizational Change Management, 23(1), 7186.

Shotter, J. (2000). Seeing Historically: Goethe and Vygotsky's 'Enabling Theory-Method'. Culture \& Psychology, 6(2), 233-252.

Shotter, J. (2006). Understanding process from within: An argument for 'withness'-thinking. Organization Studies, 27(4), 585-604.

Shotter, J. (2016). Speaking, actually: Towards a new 'fluid' common-sense understanding of relational becomings. Farnhill, UK: Everything is Connected Press.

Simpson, B., Buchan, L., \& Sillince, J. (2017). The performativity of leadership talk. Leadership, OnlineFirst, doi:10.1177/1742715017710591.

Statler, M., Roos, J., \& Victor, B. (2009). Ain't Misbehavin': Taking Play Seriously in Organizations Journal of Change Management, 9(1), 87-107.

Steyaert, C., Marti, L., \& Michels, C. (2012). Multiplicity and reflexivity in organizational research: Towards a performative approach to the visual. Qualitative Research in Organizations and Management, 7(1), 34-53.

Stierand, M. (2015). Developing creativity in practice: Explorations with world-renowned chefs. Management Learning, 46(5), 598-617. 
Thorsted, A. C. (2016). Communities of play - a collective unfolding. International Journal of Play, $5(1), 28-46$.

Tsoukas, H., \& Hatch, M. J. (2001). Complex Thinking, Complex Practice: The Case for a Narrative Approach to Organizational Complexity. Human Relations, 54(5), 979-1013.

Urry, J. (2007). Mobilities. Cambridge, UK: Polity Press.

Valsiner, J., \& van der Veer, R. (2000). The social mind: Construction of the idea. Cambridge, UK: Cambridge University Press.

Vygotsky, L. S. (1978). Mind in society (M. Cole, Trans.): Harvard University Press.

Warren, S. (2005a). Humour as a management tool. In U. Johannson \& J. Woddilla (Eds.), Irony and organizations (pp. 174-199). Koege: Copenhagen Business School Press.

Warren, S. (2005b). Photography and voice in critical qualitative management research. Accounting, Auditing \& Accountability Journal, 18(6), 861-882.

Weick, K. E. (1998). Improvisation as a Mindset for Organizational Analysis. Organization Science, 9(5), 543-555.

West, S. (2014). Play as a facilitator of organizational creativity. In E. Shiu (Ed.), Creativity research: An inter-disciplinary and multi-disciplinary research handbook (pp. 191-206). Oxford: Routledge. 